\title{
PROCESSAMENTO DA DIETA PARA LARVAS DE MANDI-PINTADO (PIMELODUS BRITSKII)
}

\author{
PROCESSING OF DIET FOR LARVAE OF PIMELODUS BRITSKII
}

Neu, D.H. ${ }^{1 *}$, Diemer, O. ${ }^{2 A}$, Sary, C. ${ }^{3}$, Reis, E.S. ${ }^{2 B}$, Feiden, A. ${ }^{1 A}$ e Boscolo, W.R. ${ }^{1 B}$

${ }^{1}$ Recursos Pesqueiros e Engenharia de Pesca. Universidade Estadual do Oeste do Paraná. Campus Toledo. 85903-160. PR-Brasil. *dacley_pesca@hotmail.com; Afeiden@seti.pr.gov.br; Bwrboscolo@hotmail.com ${ }^{2}$ Zootecnia. Universidade Estadual do Oeste do Paraná. Campus Marechal Cândido Rondon. PR-Brasil.

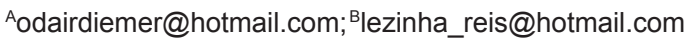

${ }^{3}$ Grupo de Estudos em Manejo na Aquicultura Gemaq. zitozootecnia@hotmail.com

\section{PalaVRas chaVe adicionais}

Aqüicultura. Desempenho. Larvicultura. Nutrição. Peixes nativos.

\section{RESUMO}

Este trabalho objetivou avaliar a influencia do processamento de ração na dieta sobre o desenvolvimento de larvas de mandi-pintado (Pimelodus britskii). Foram utilizadas 75 larvas, distribuídas em um experimento inteiramente casualizado em 15 aquários de 5 I de volume útil em uma densidade de uma larva por litro. As rações foram processadas e fornecidas na forma farelada, pastosa e extrusada moída. As larvas foram alimentadas até a saciedade aparente por um período de 30 dias, 4 vezes ao dia: 8, 11, 14 e 17 h. Os parâmetros da água (oxigênio dissolvido, $\mathrm{pH}$ e condutividade) foram mensurados uma vez por semana. Não foram observadas diferenças no desempenho das larvas em relação ao peso médio final e sobrevivência. Para o comprimento médio final, a dieta extrusada moída foi melhor que a ração farelada $(p<0,05)$, mas não diferiu da dieta pastosa. Os resultados indicam que o processamento da ração influencia no desempenho na fase inicial. Por tanto, recomenda-se a utilização de ração extrusada moída para se obter maior comprimento final dos animais.

\section{SUMMARY}

This study aimed evaluate the influence of food processing in diet on development of larvae of Pimelodus britskii. Seventy five larvae were assigned in a completely randomized design to 15

Recibido: 25-6-09. Aceptado:22-10-09.

\section{ADDICIONAL KEYWORDS}

Aquaculture. Performance. Larvae culture. Nutrition. Native fish.

aquariums of five liters at a density of one larva per liter. The diets were processed and supplied as mash, paste and extruded ground. The larvae were feeding to apparent satiation for a period of 30 days, four times daily: $8,11,14$ and $17 \mathrm{~h}$. The parameters of water (dissolved oxygen, $\mathrm{pH}$ and conductivity) were measured once a week. There were not differences in performance for final weight, and survival of larvae. For the average final length, the ground extruded diet was better than the mash diet $(p<0.05)$ but not different from the pasty diet. These results indicate that processing of the feed influence the performance of the Pimelodus britskii in the initial phase. Therefore is recommended the use of ground extrused diets to achieve higher final length of animals.

\section{INTRODUÇÃO}

O mandi-pintado (Pimelodus britskii) é uma espécie endêmica da bacia do rio Iguaçu (Garavello e Shibatta, 2007), e representa uma segunda espécie do gênero Pimelodus nesta bacia. Essa espécie antes foi confundida com Pimelodus ortmani, mas ela difere de seus congêneres pelo padrão de pigmentação.

A larvicultura é de fundamental impor-

Arch. Zootec. 60 (231): 809-812. 2011. 
tância para a obtenção de animais em quantidade e de qualidade, para as fases posteriores de criação (Meurer et al., 2003). O sucesso para a produção de rações eficientes sob o ponto de vista de crescimento e manutenção depende da identificação de ingredientes protéicos de boa qualidade e dos conhecimentos da digestibilidade dos seus nutrientes.

Três técnicas de processamento dominam a fabricação de ração na aquicultura: fareladas, peletizadas e extrusadas. Estas técnicas inevitavelmente afetam as características físicas de uma ração.

Como existe pouca informação com relação à alimentação de $P$. britskii, o objetivo desse trabalho foi avaliar a influência do processamento da dieta (farelada, extrusada moída e pastosa) para as larvas de mandi-pintado e, avaliar se o processamento da dieta influência no desempenho e na sobrevivência de larvas de mandi-pintado P. britskii.

\section{MATERIAISEMÉTODOS}

Esse trabalho foi desenvolvido no Laboratório de Aqüicultura da Unioeste, em conjunto com o Grupo de Estudos de Manejo na Aqüicultura, GEMAq, durante o período de janeiro a fevereiro de 2009.

Foram utilizadas 75 larvas de mandi-pintado P. britskii com 10 dias de idade com peso médio de $32 \pm 4,8 \mathrm{mg}$ e comprimento inicial médio de $8,22 \pm 0,40 \mathrm{~mm}$, distribuídas num delineamento inteiramente casualizado com três tratamentos e cinco repetições, em 15 aquários com capacidade para 5 litros de água, conectados com mangueiras de ar a um soprador, de onde recebia oxigênio constantemente.

As rações experimentais foram formuladas contendo $45 \%$ de proteína bruta, diferenciando-se pelo seu processamento, ração farelada, extrusada moída e pastosa.

Para a elaboração das rações, os ingredientes foram moídos em moinhos de martelo com peneiras de $0,50 \mathrm{~mm}$ de diâmetro. A ração farelada foi considerada a obtida depois do processo de moagem dos ingredientes. A ração pastosa foi considerada sendo a mesma farelada, mas no momento da alimentação esta era umedecida, com aproximadamente 1,7 partes de água para cada parte de matéria seca e distribuída aos peixes em forma de bolinhas. A ração extrusada moída foi a ração farelada, mas esta passou pelo processo de extrusão e depois novamente moída, de modo que ficassem grânulos pequenos suficientes para que as larvas se alimentassem.

A ração foi fornecida em conjunto com a artêmia por sete dias ( $33 \mathrm{ml}$ de artêmia por unidade experimental por horário de alimentação), em quatro horários (8:00, 11:00, 14:00 e 17:00 h) e, em sequência a artêmia foi retirada gradativamente da dieta das larvas. A partir do $15^{\circ}$ dia somente as rações experimentais foram fornecidas às larvas. O processo de substituição da artêmia por ração foi gradativo para que as larvas se adaptassem ao manejo alimentar.

Os aquários foram sifonados, para retirada das fezes e restos de rações, uma vez ao dia, as 17:30 h, com a remoção de cerca de $40 \%$ do volume de água. A temperatura da água foi mensurada diariamente pela manhã e pela tarde, os parâmetros da água (oxigênio dissolvido, $\mathrm{pH}$ e condutividade) uma vez por semana.

Após o término do experimento, os peixes foram pesados e medidos individualmente com auxílio de balança analítica e paquímetro, para avaliação do peso final médio, comprimento final médio e sobrevivência.

De posse desses dados de desempenho, os mesmos foram submetidos a análise de variância ANOVA e quando observados diferenças significativas $(\mathrm{p}<0,05)$, foi aplicado o teste de média de Tukey em 5\% de significância, utilizando o programa SAS, quando não apresentado normalidade, os dados foram transformados e aplicado o teste de Tukey a $5 \%$. 


\section{RESULTADOSEDISCUSSÃO}

Os parâmetros físicos e químicos da água dos aquários experimentais, temperatura $\left(24,9 \pm 0,95^{\circ} \mathrm{C}\right.$ na manhã, e $24,8 \pm 0,65^{\circ} \mathrm{C}$ na tarde), oxigênio dissolvido $(5,20 \pm 0,71$ mg..$\left.^{-1}\right), \mathrm{pH}(7,88 \pm 0,10)$ e condutividade $\left(0,23 \pm 0,18 \mu \mathrm{s} . \mathrm{cm}^{-1}\right)$ permaneceram dentro da condição normal para peixes tropicais.

Não foram observadas diferenças no peso médio final e sobrevivência dos animais. Porém, como o resultado de comprimento médio não apresentou distribuição normal, logaritimizou-se os dados e houve diferença para o comprimento $(\mathrm{p}<0,05)($ tabela I $)$.

Os dados observados discordam dos dados apresentados por Meurer et al. (2003) que trabalharam com dietas fareladas, pastosas e micropeletizadas na alimentação de larvas de tilápia durante a fase de reversão sexual, os autores relatam que a dieta farelada proporcionou melhor comprimento final, mas não diferiu quanto ao peso, já a sobrevivência foi menor nos peixes alimentados com a dieta micropeletizada.

Um dos motivos que pode ter contribuído para a dieta extrusada moída apresentar melhoria no crescimento dos peixes é o fato dela ter passado pelo processo de extrusão, que proporciona maior estabilidade e disponibilidade de seus nutrientes devido às mudanças físicas que ocorrem através do aquecimento e, novamente ser moída, tornando os grânulos menores, e desse modo fazendo com que os peixes tivessem maior facilidade de se alimentar.

Para larvas de mandi-pintado observouse efeito benéfico da ração extrusada, os peixes alimentados com ração extrusada moída possivelmente atingiram o comprimento maior pelo fato dos animais aproveitarem melhor os ingredientes, isso porque a ração farelada e pastosa pode sofrer perdas de nutrientes por lixiviação ou a seletividade dos ingredientes alimentares proporcionada pelo processamento da dieta pode ter influenciado o desempenho da espécie.

Como os alimentos utilizados neste experimento foram moídos em triturador com peneiras de $0,50 \mathrm{~mm}$, subentendeu-se que os grânulos ficaram menores que esse diâmetro, Gentelini et al. (2005) estudando o grau de moagem de dietas para alevinos de piavuçu, não observaram diferenças significativas entre os tratamentos, os peixes se alimentavam sem dificuldades quando os ingredientes das rações foram moídos e triturados em moinho com peneiras entre 0,5 e 1,50 mm de diâmetro. Para as larvas de mandi-pintado a moagem dos ingredientes em $0,50 \mathrm{~mm}$ proporcionou boa captura dos alimentos resultando em bom desempenho dos peixes, não sendo observadas diferenças significativas $(p>0,05)$ para a sobrevivência e para o ganho de peso dos animais alimentados com os diferentes tipos de rações processadas.

Tabela I. Valores de desempenho e sobrevivência das larvas de mandi-pintado submetidas à rações com diferentes processamentos. (Performance and survival values of larvae Pimelodus britskii submitted to the rations with different processing).

\begin{tabular}{lccccc}
\hline Rações & Pastosa & Farelada & Extrusada moída & $F(p)$ & C.V. \\
Peso $(\mathrm{mg})$ & & & & & \\
Comprimento $(\mathrm{mm})$ & $84,47 \pm 26,25^{\mathrm{a}}$ & $77,43 \pm 21,81^{\mathrm{a}}$ & $94,38 \pm 31,51^{\mathrm{a}}$ & $2,32(0,10)$ & 31,38 \\
Sobrevivencia $(\%)$ & $22,52 \pm 2,01^{\mathrm{ab}}$ & $22,28 \pm 2,03^{\mathrm{b}}$ & $23,95 \pm 2,41^{\mathrm{a}}$ & $4,02(0,02)$ & 9,42 \\
& $92^{\mathrm{a}}$ & $92^{\mathrm{a}}$ & $92^{\mathrm{a}}$ & $0,0(1,0)$ & 30,09 \\
\hline
\end{tabular}

Valores com letras iguais em uma mesma linha não diferem estatisticamente de acordo com o teste de Tukey $(p>0,05)$. 


\section{NEU, DIEMER,SARY, REIS, FEIDEN E BOSCOLO}

Nota-se que as larvas de mandi-pintado, chegaram a um peso e comprimento final não tão elevado como relatado por Feiden et al. (2006) estudando larvas de surubim do Iguaçu (Steindachneridion melanodernatum) que obtiveram peso e comprimento final de $659 \mathrm{mg}$ e $38 \mathrm{~mm}$ respectivamente, estas larvas foram alimentadas com artêmia e ração que proveu um maior desenvolvimento e maior sobrevivência às larvas de surubim. O que pode se predisser com isso é que larvas de mandi-pintado, por ser peixe de couro, ter hábito onívoro e ser da mesma família do surubim (Pimelodidae), possam necessitar de maior tempo de alimentação com artêmia, demonstrando que a maioria dos nutrientes exigidos pelas larvas é fornecida mais adequadamente quando ambas as dietas são fornecidas juntamente.

Vários autores relatam a importância do alimento vivo nas fases iniciais de cultivo, e quando maior o tempo disponibilizando

\section{BIBLIOGRAFIA}

Feiden, A., Hayashi, C. e Boscolo, W.R. 2006. Desenvolvimento de larvas de surubim-doiguaçu (Steindachneridion melanodernatum) submetidas a diferentes dietas. Rev. Bras. Zootecn., 35: 2203-2210.

Garavello, J.C. and Shibatta, O.A. 2007. A new species of the genus Pimelodus La Cépède, 1803 from de rio Iguaçu basin and a reappraisal of Pimelodus ortmani Haseman, 1911 from de rio Paraná system, Brazil (Ostariophysi: Siluriformes: Pimelodidade). Neotrop. Ichthyol., 5: 282-292.

Gentelini, A.L., Boscolo, W.R., Feiden, A., Meurer, F. e Hayashi, C. 2005. Graus de moagem dos ingredientes em rações peletizadas para esses alimentos, melhores são as taxas de sobrevivência dos animais. Acredita-se que as larvas de mandi-pintado necessitam desses organismos na sua alimentação inicial, pois conforme relatado por Kim et al. (1996) a presença de enzimas proteolíticas na artemia viva apresenta vantagens na digestibilidade em comparação a alimentos artificiais. Segundo Luz e Zaniboni-Filho (2001) uma das maiores dificuldades da larvicultura é a alimentação, pois para a maioria das espécies a alimentação está relacionada com a inclusão de organismos vivos. Entretanto, o processamento das dietas e a forma de fornecimento podem influenciar de diversas maneiras o desempenho dos animais.

\section{CONCLUSÃO}

Durante o período de larvicultura da espécie Pimelodus britskii recomenda-se o processamento das dietas na forma extrusada seguida de moagem para obter maior comprimento final dos animais.

alevinos de piavuçu (Leporinus macrocephalus). Acta Sci. Ani. Sci., 27: 93-97.

Kim, J., Masse, K.C. and Hardy, R.W. 1996. Adult Artemia as food first feeding cocho salmon (Oncorhynchus kisutch). Aquaculture, 144: 217-226.

Luz, R.K. e Zaniboni-Filho, E. 2001. Utilização de diferentes dietas na primeira alimentação de mandi-amarelo (Pimelodus maculatus, Lacépéde). Acta Sci., 23: 483-489.

Meurer, F., Hayashi, C. e Boscolo, W.R. 2003. Influencia do processamento da ração no desempenho e sobrevivência da tilápia do nilo durante a reversão sexual. Rev. Bras. Zootecn., 32: $262-267$. 